\title{
XLII. Air-pressures used in playing brass instruments
}

\author{
Edwin H. Barton D.Sc. F.R.S.E. \& S.C. Laws B.Sc.
}

To cite this article: Edwin H. Barton D.Sc. F.R.S.E. \& S.C. Laws B.Sc. (1902) XLII. Air-pressures used in playing brass instruments, Philosophical Magazine Series 6, 3:16, 385-393, DOI: 10.1080/14786440209462778

To link to this article: http://dx.doi.org/10.1080/14786440209462778

册 Published online: 15 Apr 2009.

Submit your article to this journal $[\pi$

Џ Article views: 2

Q View related articles $\asymp$ 
for the wet bulb. It cannot compete in simplicity with the wet bulb in its simplest form, but it can compete with the various modifications (whirled thermometers, \&c.).

For the range studied the constant .93 can be used for $k$, and it is hoped that this will be tested for other climates and below the freezing-point. A small error in $k$ is of very little importance, owing to the small value of $t-\theta$.

(7) Conclusion.- The method has been shown simple; the elementary theory is thought rigorous; the extension to small thermal effects is justified in numerous experiments; $k$ has turned out to be very nearly 93 over as wide a range as was open to study; $c$ is unexpectędly low. The last point requires some discussion. According to a mass of published dew-point observations, a value 0.5 for $c$ was expected in Table I.l., and the writer thinks it superfluous to make additional dew-point observations. The low value 0.4 found for $c$, though opposed somewhat to the dew-point results, is favoured by Maxwell's theory*. To make $c=.5$ in high ventilation is to make his ratio $\frac{\mathrm{K}}{\overline{\mathrm{D}}}$ (loc. cit.) practically unity, but he considers it probably $\cdot 77$ and "certainly less than unity." His estimate is supported by the experiments of Graetz, Winkelmann, and of Kundt and Warburg, so that a considerably lower value of $c$ is suggested. It is not, however, the object of this note to determine the value of $\mathrm{c}$. It is the method with its theoretical and practical claims which is put forward. A wider basis was rendered impossible from want of leisure.

Abbasia Observatory, Egypt.

August 22, 1901.

XLII. Air-Pressures used in playing Brass Instruments. By Edwin H. Barton, D.Sc., F.R.S.E., Senior Lecturer in Physics at University College, Nottingham, and S. C. Laws, B. Sc., "1851 Exhibition" Science Research Scholar †.

\section{[Plates VII. \& VIII.]}

$\mathrm{TT}$ is well known that in playing upon the "brass" or 1 "wood-wind" instruments of the orchestra the particular note, at any instant desired, is prodnced by the simultaneous use of the mechanism of the instrument and the corresponding " embouchure," through which air at a suitable pressure is driven by the performer. The mechanism adjusts the

* Art. "Diffusion," Encyc. Britt.

+ Communicated by the Physical Society: read December 13, 1901. 
length of the tubing in use so that the note in question is one of those with which the instrument is now in resonance. The correct embouchure and air-pressure pick out, as it were, from the notes then possible to the instrument, the particular one sought, and cause it to sound.

Some of the problems here involved are chiefly of a musical character.

But the pressure of air which solicits the desired note, although several others are possible with the same fingering, and the variations of this pressure with the pitch, loudness, and other circumstances form a problem belonging rather to the domain of physics, and one which is attacked in the experiments here described.

Some previous work on the air-pressures required for various instruments has been done by Dr. W. H. Stone (see p. 171, 'Elementary Lessons on Sound,' Macmillans, 1891), who gives maximum and minimum pressures for the oboe, clarinet, bassoon, horn, cornet, trumpet, euphonium, and bombardon. No details, however, are there given of the pressures for each note of the scale, nor of the variations of the pressure with loudness.

The present work deals with three brass instruments, viz., the tenor trombone, the trumpet, and the cornet. The results of the experiments on these are sufficiently consistent to support certain general conclusions which are summarized at the close of the paper.

Experimental Method.-Following the hint given by Dr. Stone, the pressures were taken by a water-manometer connected to the performer's mouth by an indiarubber tube terminating in a glass nozzle which could be held by the side teeth. After a little practice, the instrument could be played without the insertion of this side nozzle producing any serious annoyance. The open end of the manometer was provided with a plug of cork and cotton-wool which just damped out the osciliations of the water columns in it without interfering with their prompt assumption of the correct levels when a note was sounded. To arrest the columns immediately in these positions and retain them there until the readings were taken, a pinch-cock was used on the indiarubber pipe connecting the manometer with the player's mouth. Thus the modus operandi was as follows:A series of notes and their loudness being decided upon and indicated in the note-book and the player and recorder in position, the recorder calls for a certain note, at the same time opening the pinch-cock. The player sounds the note and sustains it till it is judged to be of the desired intensity; the pinch-cock is then released, thus immediately closing 
used in playing Brass Instruments.

and so retaining the water columns in place. These are read and recorded and then the next note is called for.

The manometer-scales were graduated to centimetres and estimated to quarters of a division.

A mercury manometer was tried for some of the higher pressures exceeding a metre of water, but was quickly abandoned as being far less convenient.

Lines of Investigation. - It was decided to find how the air-pressure required to sound the different notes varied with (1) the pitch of the note, (2) its loudness, (3) the fingering or other manipulation of the instrument, (4) on the instrument itself. In each of these cases of inquiry as to the effect of any one variable cause, the other variables were kept constant so far as circumstances permitted. Thus, to test how the pressure depended upon pitch, a scale was played with the loudness maintained as nearly as possible the same. The fingering was, however, necessarily changed to produce the consecutive notes of the scale. Again, for dependence of pressure on londness, the same note was played with various intensities, then another note with various intensities, and so on. Thirdly, where the same note was obtainable with two fingerings, the sound was obtained of the given pitch and with the same intensity, first with the usual and then with the alternate fingering.

The Scale on Brass Instruments.-In order to render subsequent references quite clear, it seems desirable to explain here how the scale is obtained both with slide and valve instruments. In the slide instruments, when the slide is in the first position, $i$. e. closed, the minimum length of tubing is in use, and the only notes obtainable are those with which that length of tubing is in resonance. These form the harmonic series, the relative frequencies of the notes being 1,2 , $3,4,5,6$, \&c. ; the fundamental or prime is termed by musicians the "pedal" and is rarely used. By drawing the slide out to the second position, sufficient length of tubing is introduced to put the instrument in resonance with notes a semitone lower. The other positions to the seventh inclusive lower the notes of the instrument by a tone, a tone and a half, \&c. to three tones respectively. The use of the slide has thus three effects: (1) it furnishes the complete chromatic scale in the largest interval which occurs between the notes in use natural to the instrument with the slide closed, viz., between the second and third harmonics, whose interval is a fifth ; (2) and consequently it more than bridges all the other intervals (fourth, major third, \&c.) which occur in the higher part of the harmonic series, thus giving alternate methods of playing various notes ; (3) it extends the scale downwards. 
In valve instruments the same results are usually approximately obtained by the use of three valves. The first valve, when depressed, adds sufficient tubing to lower the notes by a whole tone, the second valve a semitone only, and the third about a tone and a half.

These facts are exhibited collectively in Table $I$. for an instrument tuned to $\mathrm{B}$ ? like the Cornet and Tenor Trombone. The lower notes are at the bottom of the table. Those in round brackets indicate alternative fingerings. The numerals under some of the notes give approximate frequencies for the trombone in complete vibrations per second. For the cornet, all these require doubling.

TABLE I.-The Scale on Slide and Valve Instruments.

\begin{tabular}{|c|c|c|c|c|c|c|c|}
\hline $\begin{array}{c}\text { Positions of Slide } \\
\text { on 'Trombone. }\end{array}$ & 1st. & 2nd. & 3rd. & 4th. & 5th. & 6th. & 7 th. \\
\hline $\begin{array}{l}\text { Valves depressed } \\
\text { on Cornet. }\end{array}$ & None. & 2nd. & Ist. & $\begin{array}{l}\text { 1st \& } \\
\text { 2nd. }\end{array}$ & $\begin{array}{l}\text { 1st \& } \\
\text { 3rd. }\end{array}$ & $\begin{array}{l}\text { 2nd \& } \\
\text { 3rd. }\end{array}$ & $\begin{array}{l}\text { 1st, 2nd, } \\
\text { \& 3rd. }\end{array}$ \\
\hline $\begin{array}{c}\text { Number of partial } \\
\text { tone or } \\
\text { " Harmonic" } \\
\text { elicited by suitable } \\
\text { "embouchure" } \\
\text { and air-pressure. }\end{array}$ & & & & Names of & Notes. & & \\
\hline 8 & $\begin{array}{l}\mathrm{Bt} \\
480\end{array}$ & $A$ & & G & & & \\
\hline 7 & $\begin{array}{r}\text { This } \\
\text { general }\end{array}$ & $\begin{array}{l}\text { harmo } \\
\text { ly used }\end{array}$ & nic is & not & & & \\
\hline 6 & $\underset{360}{F}$ & $\mathbf{E}$ & & (D) & & & \\
\hline 5 & $\begin{array}{l}\mathrm{D} \\
300\end{array}$ & & C & & $\begin{array}{l}(\mathrm{B} b) \\
240\end{array}$ & & \\
\hline 4 & $\begin{array}{l}\mathrm{B}_{6} \\
240\end{array}$ & $\mathbf{A}$ & & G & & $\begin{array}{l}\text { (F) } \\
180\end{array}$ & \\
\hline 3 & $\begin{array}{l}F \\
180\end{array}$ & $\mathbf{E}$ & & D & & C & B \\
\hline 2 & $\begin{array}{l}\mathrm{B} p_{2} \\
120\end{array}$ & $A$ & & G & & $\mathrm{F}$ & $\mathbf{E}$ \\
\hline 1 & $\begin{array}{l}\mathbf{B} z \\
60\end{array}$ & $\begin{array}{r}\text { This } \\
\text { is not }\end{array}$ & $\begin{array}{l}\text { prime } \\
\text { genera }\end{array}$ & $\begin{array}{l}\text { note, cal } \\
\text { lly used. }\end{array}$ & Ied the & "pedal," & \\
\hline
\end{tabular}


Experimental Results. Tenor Trombone.-The instrument used for these experiments is in Bb by Millereau \& Co. of Paris, and was throughout played by $\mathrm{E}$. H. Barton with a Higham mouthpiece.

The mean results of scales and exercises over two octaves tried on it at different intensities are given in Table II., and graphically exhibited in Plate VII. The ordinates of the curves are the manometer pressures in centimetres of water, and the abscissæ represent the intervals in cents, the intonation being assumed in equal temperament.

Both in the table and on the Plate the $\mathrm{C}$ in square brackets is the middle $\mathrm{C}$ between the staves, and is of frequency about 269 complete vibrations per second.

TABLE II.-Pressures for Scales on Trombone.

\begin{tabular}{|c|c|c|c|c|c|c|c|c|c|c|c|c|c|c|c|}
\hline Notes $\ldots . .$. & $\mathrm{F}$ & $\mathrm{G}$ & $A$ & $\mathrm{~B} b$ & $\mathbf{C}$ & $D$ & $\mathbf{E}$ & $\mathrm{F}$ & $G$ & $A$ & $\mathrm{~B} b$ & {$[\mathrm{C}]$} & D & $\mathbf{E}$ & $\mathbf{F}$ \\
\hline $\left.\begin{array}{l}\text { Positions } \\
\text { of Slide. }\end{array}\right\}$ & 6 & 4 & 2 & 1 & 6 & 4 & 2 & 1 & 4 & 2 & 1 & 3 & 1 & 2 & 1 \\
\hline$f$ & & & & & & & & & & & & & & & \\
\hline $\left.\begin{array}{c}\text { Mean of } \\
4 \text { sets. }\end{array}\right\}$ & 18 & 26 & 32 & 37 & 40 & 47 & 53 & 58 & 65 & 73 & 80 & 88 & 108 & 117 & [122] \\
\hline $\begin{array}{c}m . \\
\text { Mean of } \\
11 \text { sete. }\end{array}$ & 17 & 23 & 27 & 31 & 34 & 42 & 51 & 52 & 57 & 637 & $64 \cdot 2$ & 71 & 76 & 81 & 90 \\
\hline $\left.\begin{array}{c}p . \\
\text { Mean of } \\
4 \text { sets. }\end{array}\right\}$ & 13 & 17 & 22 & 27 & $27 \cdot 5$ & 35 & 42 & 39 & 44 & 48 & $45 \cdot 5$ & 52 & 59 & 65 & 74 \\
\hline
\end{tabular}

The results of experiments on given notes sounded in close succession but with different intensities are given in Table III. (p. 390).

The experiments as to change, if any, of pressure with change of fingering are detailed in Table IV. (p. 390).

Cornet.-These experiments were made with a Higham Cornet played by a professional trumpeter and cornettist, Mr. E. C. Pickerill of Nottingham. The results for scales over two octaves soft, medium, and loud, each played once only, are shown by the three curves on Plate VIII. marked respectively $p, m$, and $f$. The $\mathrm{C}$ in square brackets denotes the middle $\mathrm{C}$ between the staves. The abscissæe and ordinates are as in Plate VII. 
390 Dr. Barton and Mr. Laws on Air-Pressures

TABLe III.-Pressures for given Notes, Loud and Soft.

\begin{tabular}{|c|c|c|c|c|c|}
\hline Notes .... & $\mathbf{F}$ & BD & $\mathbf{F}$ & Bb & D \\
\hline $\begin{array}{r}\text { Approximate } \\
\text { frequencies. }\end{array}$ & 90 & 120 & 180 & 240 & 300 \\
\hline $\begin{array}{l}\text { Positions of } \\
\text { Slide. }\end{array}$ & 6 & 1 & 1 & 1 & 1 \\
\hline$p p$. & 13 & $24 *$ & 27 & 50 & $73 \cdot 5$ \\
\hline$p$ & 18 & $34 \cdot 5$ & 50 & 57 & 83 \\
\hline$m$. & $19 \cdot 5$ & $36 \cdot 5 t$ & $55 \cdot 5$ & 63 & $88 \cdot 5$ \\
\hline$f$. & 23 & 40 & $67 \cdot 5$ & 82 & 106 \\
\hline $\left.\begin{array}{c}\text { Single } \\
\text { erescendo } \\
\text { notes. }\end{array}\right\}$ & & $\begin{array}{cc}p p & 20 \\
\text { to } & \text { to } \\
f & 38\end{array}$ & $\left.\begin{array}{cc}p & 50 \\
\text { to } & \text { to } \\
f f & 78\end{array}\right\}$ & $\left.\begin{array}{rr}p & 61 \\
\text { to } & \text { to } \\
f f & 101\end{array}\right\}$ & \\
\hline
\end{tabular}

* This pressure was obtained with a small aperture between the lips. With a larger aperture, the note still being $p p$, the pressure fell to 15 !

+ The pedal note an octave lower than this was produced $m$ with a pressure of $7 \mathrm{~cm}$.

TABLE IV.-Pressures for same Notes in Alternative Positions.

\begin{tabular}{|c|c|c|c|c|c|c|}
\hline Note $\ldots . .$. & \multicolumn{2}{|c|}{$\mathrm{F}$} & \multicolumn{2}{|c|}{$\mathbf{B b}$} & \multicolumn{2}{|c|}{ D } \\
\hline $\begin{array}{l}\text { Approximate } \\
\text { frequencies. }\end{array}$ & \multicolumn{2}{|c|}{180} & \multicolumn{2}{|c|}{240} & \multicolumn{2}{|c|}{300} \\
\hline $\begin{array}{l}\text { Positions of } \\
\text { Slide. }\end{array}$ & 1 & 6 & 1 & 5 & 1 & 4 \\
\hline $\begin{array}{l}\text { No. of "Har- } \\
\text { monic" used }\end{array}$ & 3 & 4 & 4 & 5 & 5 & 6 \\
\hline$\dot{5}$ & $50 \cdot 5$ & 48 & 72 & 70 & 72 & 67 \\
\hline$m f$ & 50 & 50 & 75 & 75 & 98 & 92 \\
\hline 竞 & 73 & 68 & 94 & 92 & 119 & 117 \\
\hline$f f$ & 80 & 83 & 113 & 110 & & \\
\hline $\begin{array}{c}2 \text { nd Series } \\
(1901)\end{array}$ & 55 & 50 & 67.5 & $68 \cdot 5$ & 72 & 72 \\
\hline
\end{tabular}


The experiments on the cornet as to different intensities of given notes are detailed in Table $\mathrm{V}$.

TABLE V.-Pressures for given Notes, Loud and Soft.

\begin{tabular}{|c|c|c|c|c|c|c|}
\hline \multicolumn{2}{|c|}{ Notes ....... } & A & $\mathrm{E}$ & A & $\mathrm{CH}$ & $\mathbf{E}$ \\
\hline \multicolumn{2}{|c|}{$\begin{array}{l}\text { Approximate } \\
\text { frequencies. }\end{array}$} & 226 & 839 & 452 & 568 & 678 \\
\hline & & \multicolumn{5}{|c|}{ Pressures. } \\
\hline \multirow{3}{*}{ 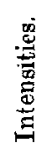 } & $f$ & 2675 & $34 \cdot 25$ & 44 & $52 \cdot 75$ & 66 \\
\hline & $m$ & $22 \div 5$ & 26 & $31 \cdot 5$ & $38 \cdot 75$ & 415 \\
\hline & $p$ & 12 & $15 \cdot 5$ & 205 & $30 \cdot 25$ & 34 \\
\hline
\end{tabular}

Trumpet.-For the experiments on the Trumpet a Besson trumpet in F was used, played by Mr. E. C. Pickerill with a mouthpiece by $H$. Keats \& Son. The results of once playing the scale in $\mathrm{F}$ through two octaves at medium intensity is shown on Plate VIII. by the dotted curve marked TT.

Comparison of Trumpet and Cornet.-Table Vl. gives the result of a comparison of trumpet and cornet as to the pressures for given notes of different intensities.

Table VI.-Trumpet and Cornet compared.

\begin{tabular}{|c|c|c|c|c|c|c|}
\hline \multicolumn{2}{|c|}{ Notes ....... } & $B t$ & $\mathrm{~F}$ & Bb & D & $\mathbf{F}$ \\
\hline \multicolumn{2}{|c|}{$\begin{array}{l}\text { Approximate } \\
\text { frequencies. }\end{array}$} & 240 & 360 & 480 & 600 & 720 \\
\hline \multirow{3}{*}{ 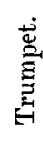 } & $f$ & 2575 & 4375 & 455 & $48 \cdot 75$ & 68 \\
\hline & $m$ & $23 \cdot 25$ & 28 & 345 & $41 \cdot 5$ & $57 \cdot 25$ \\
\hline & $p$ & 16 & 18.5 & 2675 & $28 \cdot 75$ & 42 \\
\hline \multirow{3}{*}{ हूँ } & $f$ & $26 \cdot 5$ & 45 & $47 \cdot 25$ & $55 \cdot 75$ & $75 \cdot 75$ \\
\hline & $m$ & 18 & $28 \cdot 5$ & 32.75 & 41 & $51 \cdot 75$ \\
\hline & $p$ & 13 & 24 & 225 & $32 \cdot 25$ & $39 \cdot 25$ \\
\hline
\end{tabular}


Conclusion.-In reviewing the results of the experiments it is clear that the following general interences may be drawn :-

1. Other things being equal, the louder the note the greater the pressure, as was to be expected. See Tables III., IV., V., and VI.

2. Again, all else being retained the same, the higher the pitch of the note played on a given instrument the greater the air-pressure used. See Tables III., V., and VI.

In the scales (Table II. and Pls. VII. \& VIII.) this is sometimes apparently violated, not only on the trombone played by the writer but also in the professional playing of the trumpet and cornet. This seems to be due to a slight unintentional difference in intensity or in the manner of producing the notes. (See first footnote to Table III.) In the higher parts of the scale it is hard to avoid increasing the loudness. This may account for the upward turn of the curves at this part.

3. In the preliminary experiments, on plotting the frequency of the notes of the scale as abscissæ and the pressures as ordinates fairly smooth curves were obtained convex upwards. When, however, quantities proportiona' to the logarithms of the frequencies are taken for abscissæ, the curves become almost straight lines. See Pls. VII. \& VIII., in which the abscissæ are Mr. Ellis's logarithmic cents, 100 to the equallytempered semitone, represented by the large squares, and the intonation is assumed to be in equal temperament.

4. Now if the logarithms of the frequencies be taken to measure pitches of notes, then the difference of logarithms measures the ratios of frequencies, $i$. e. measures the intervals between them. And, as is well known, this is the only way which admits of simple addition of numbers representing the component intervals giving the number representing the re. sultant interval. Thus the logarithm of the frequency is in a certain very real and important sense the besi physical measure of the pitch of a note. Hence, adopting this method, and noting that the curves in Pls. VII. \& VIII. are nearly straight lines, we may say that the air-pressure required to sound any note with given intensity is approximately proportional to its pitch defined logarithmically.

5. Where alternative positions or fingerings are used for the same noie the pressures are practically the same, see Table IV., the results in which were confirmed also by Mr. Pickerill with his instruments. In other words, it is almost indifferent as regards pressure required, whether a note is played on a given instrument as the third harmonic 
of a short tube or the fourth of a longer one, \&c., \&c. This is contrary to what is implied by some writers.

6. The pressures for identical notes on trumpet and cornet are almost the same for any given intensity, but very much less than those for the same notes on the trombone. See Table VI. and Plate VIII. (cf. with Table III. and Plate VII.).

7. The pressures used for loud low notes may exceed those for soft high notes, in some cases even where the notes are an octave apart. See Tables III., IV., V., and VI., also Pls. VII. \& VIII.

8 . The present results as to maximum and minimum pressures are in accord with Dr. Stone's, so far as comparison is possible.

Our thanks are due to Mr. Pickerill for kindly placing his services at our disposal.

University College, Nottingham, August 1901.

XLIII. The Induction Coil. By Prof. John Trowbridge**

T ORD Rayleigh, in a recent article (Philosophical 11 Magazine, Dec. 1901), has shown the significance of the electrostatic capacity between the primary and the secondary of the induction-coil, and has proved that in certain cases a condenser in the primary is of no advantage, and in certain cases may be prejudicial.'

The performance of a powerful coil devised by Mr. Heinze, of Boston, U.S., for me, operated by his liquid interrupter, justifies the points raised by Lord Rayleigh ; and, on account of the importance of the induction-coil in wireless telegraphy, merits I think wider knowledge than it has received.

The dimensions of the coil are as follows :-

Jength of iron of primary coil, 48 inches.

Diameter of " $, \quad, 3 \frac{1}{2}$,

Wound with one layer of no." 6 copper "wire.

The secondary coil consists of 140 coils separated from each other by plates of glass one eighth of an inch thick. Each of these coils is wound with, between 400 and 500 turns, fine wire. The entire resistance of the secondary coil is $246,600 \mathrm{ohms}$.

The secondary is merely inclosed in a box. By unscrewing the cover of this box the sectional coils can be inspected, and any sectional coil can be removed if its insulation breaks down; for the coils are not imbedded in paraffin. It was * Communicated by the Author.

Phil. Mag. S. 6. Vol. 3. No. 16. April 1902. 
Phil, Mag. Ser. 6, Vol. 3, Pl. VII.

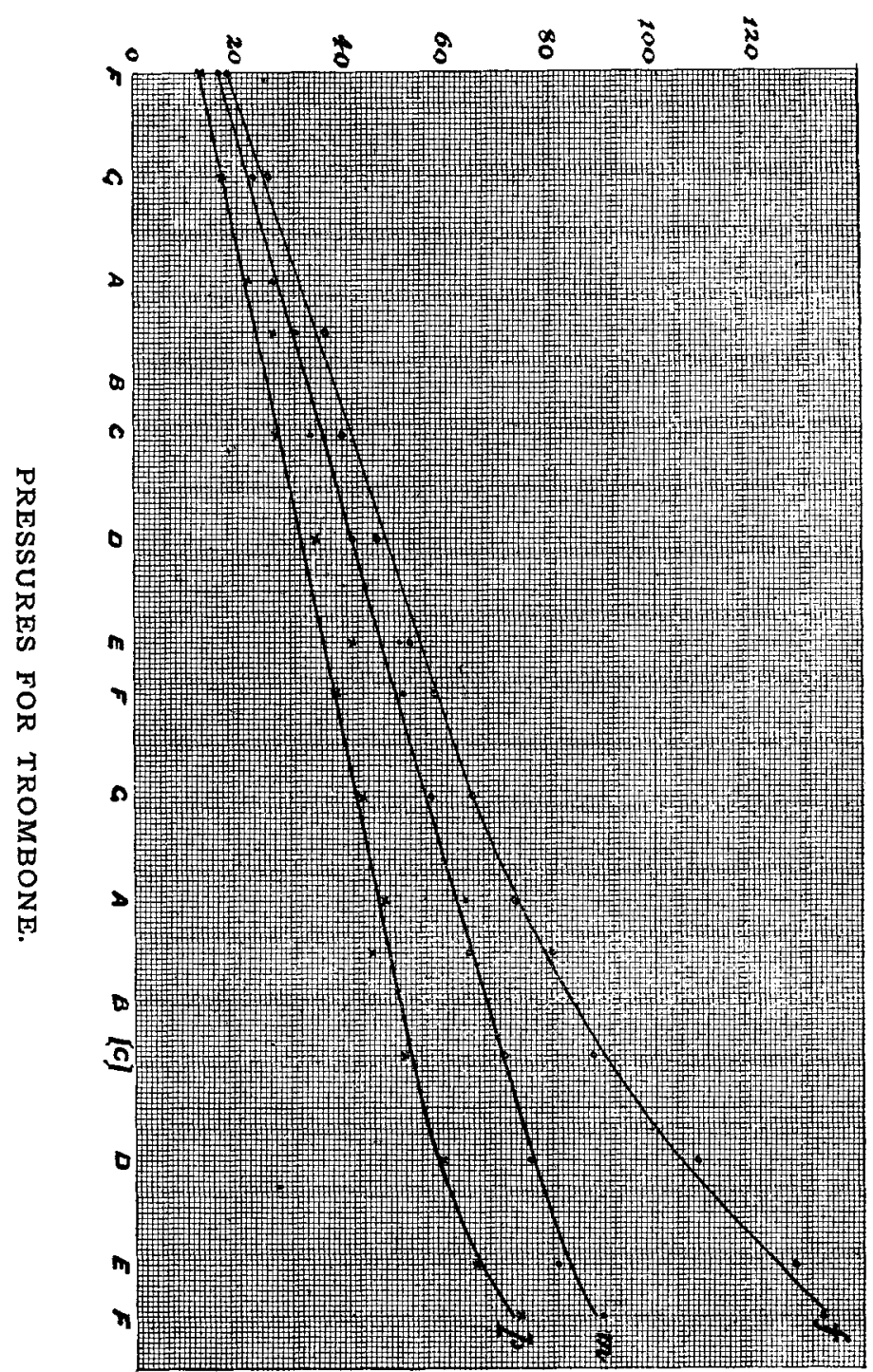


Phil. Mag. Ser, 6. Vol, 3. Pl. VIII.

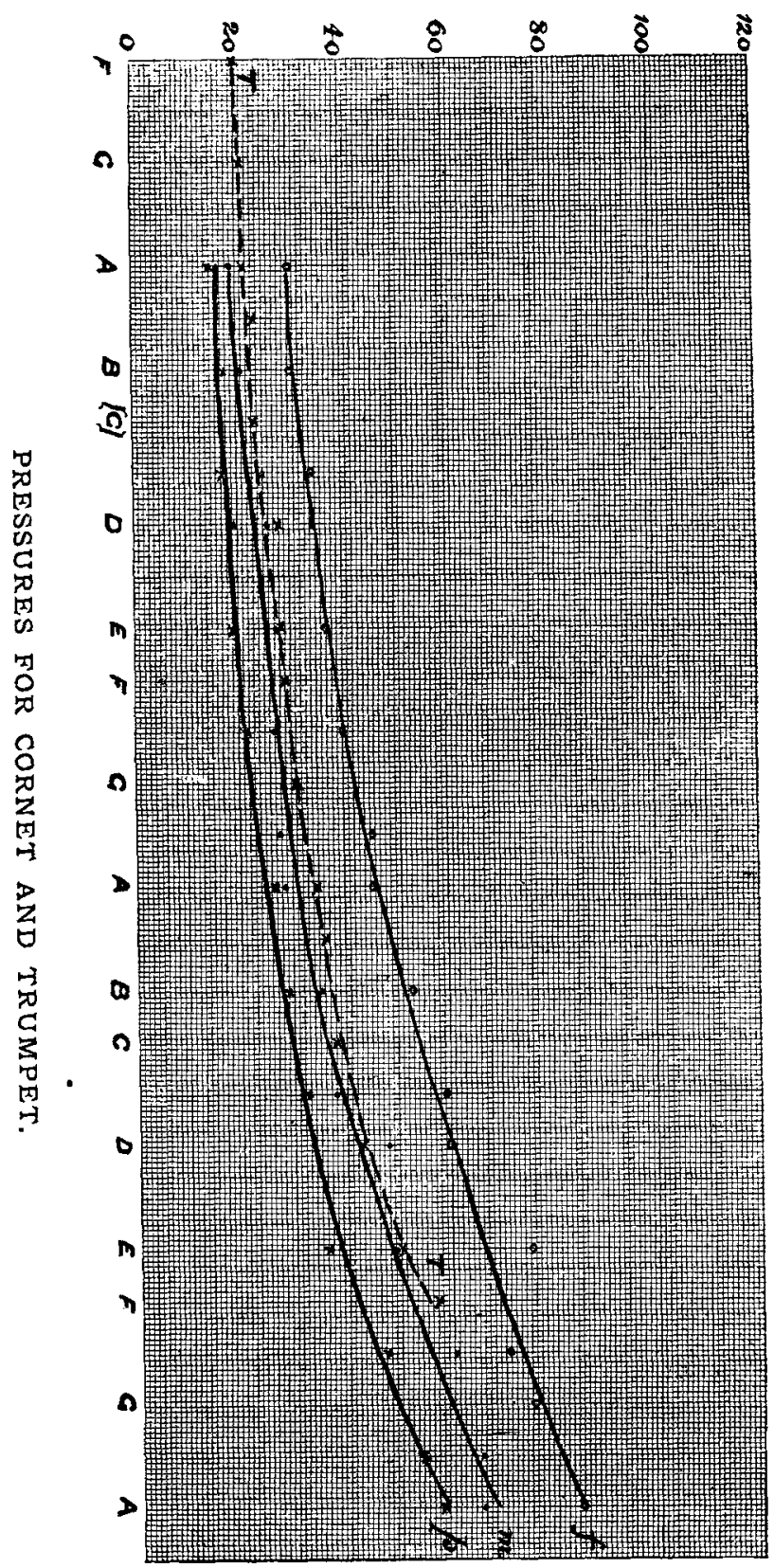

